\title{
Impacts of the Manaus pollution plume on the microphysical properties of Amazonian warm-phase clouds in the wet season
}

Micael A. Cecchini et al.

Correspondence to: Micael A. Cecchini (micael.cecchini@cptec.inpe.br)

The copyright of individual parts of the supplement might differ from the CC-BY 3.0 licence. 


\section{Supplement}

This supplement document contains figures that detail the DSD measurements above rivers or land. It is intended to show the river breeze effect on the DSDs and also that the Manaus plume effect is significant even taking into account the local river breeze.
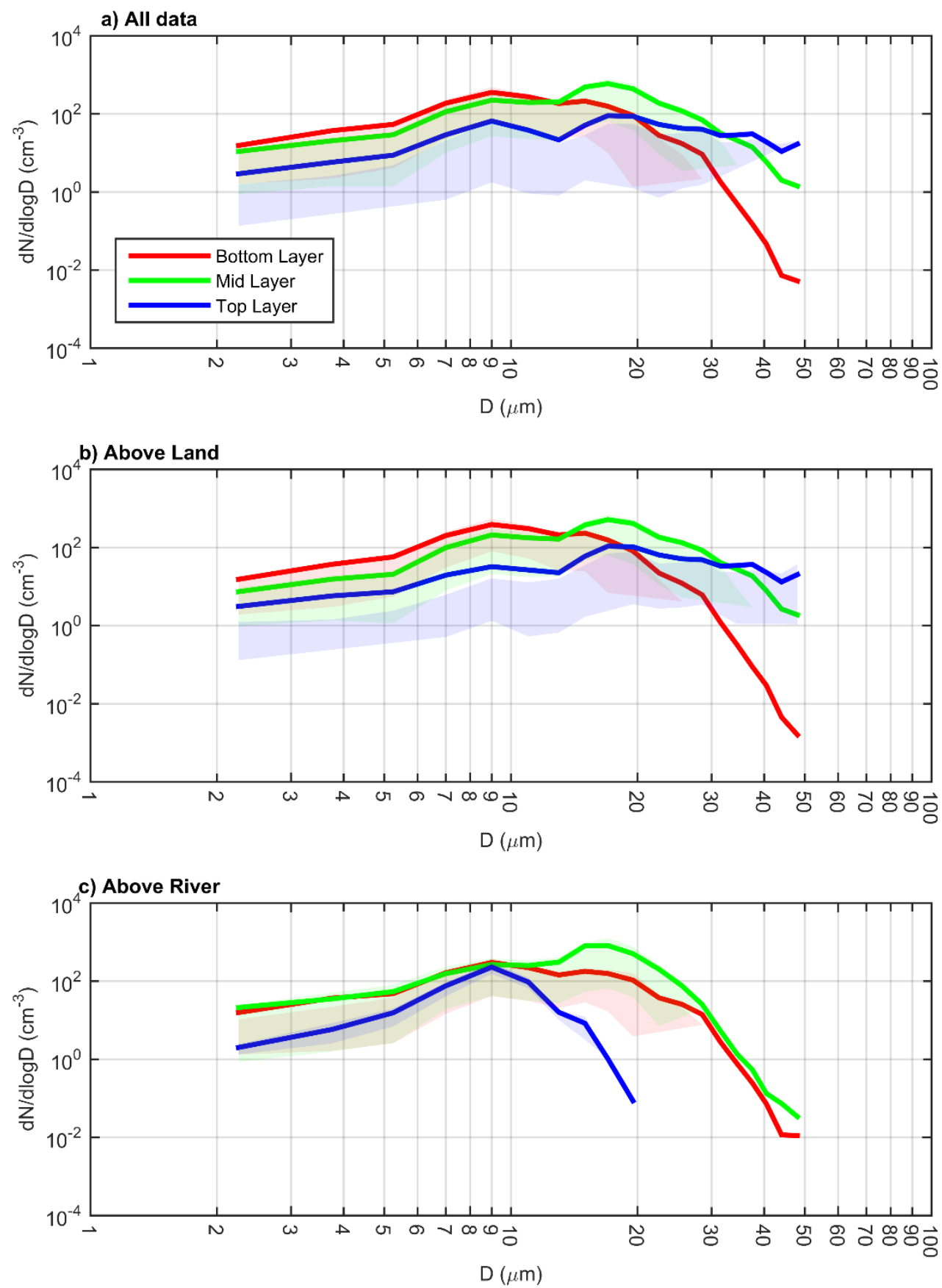
Figure S1: averaged DSDs for the layers defined as bottom, mid and top of the clouds. The relative altitude ( $0 \%$ for cloud base and $100 \%$ for the $0^{\circ} \mathrm{C}$ isotherm height) ranges for the layers are $0-20 \%, 20-50 \%$ and $50-100 \%$, respectively. a) all data, b) only DSDs measured above land and c) only DSDs observed in clouds over the rivers.
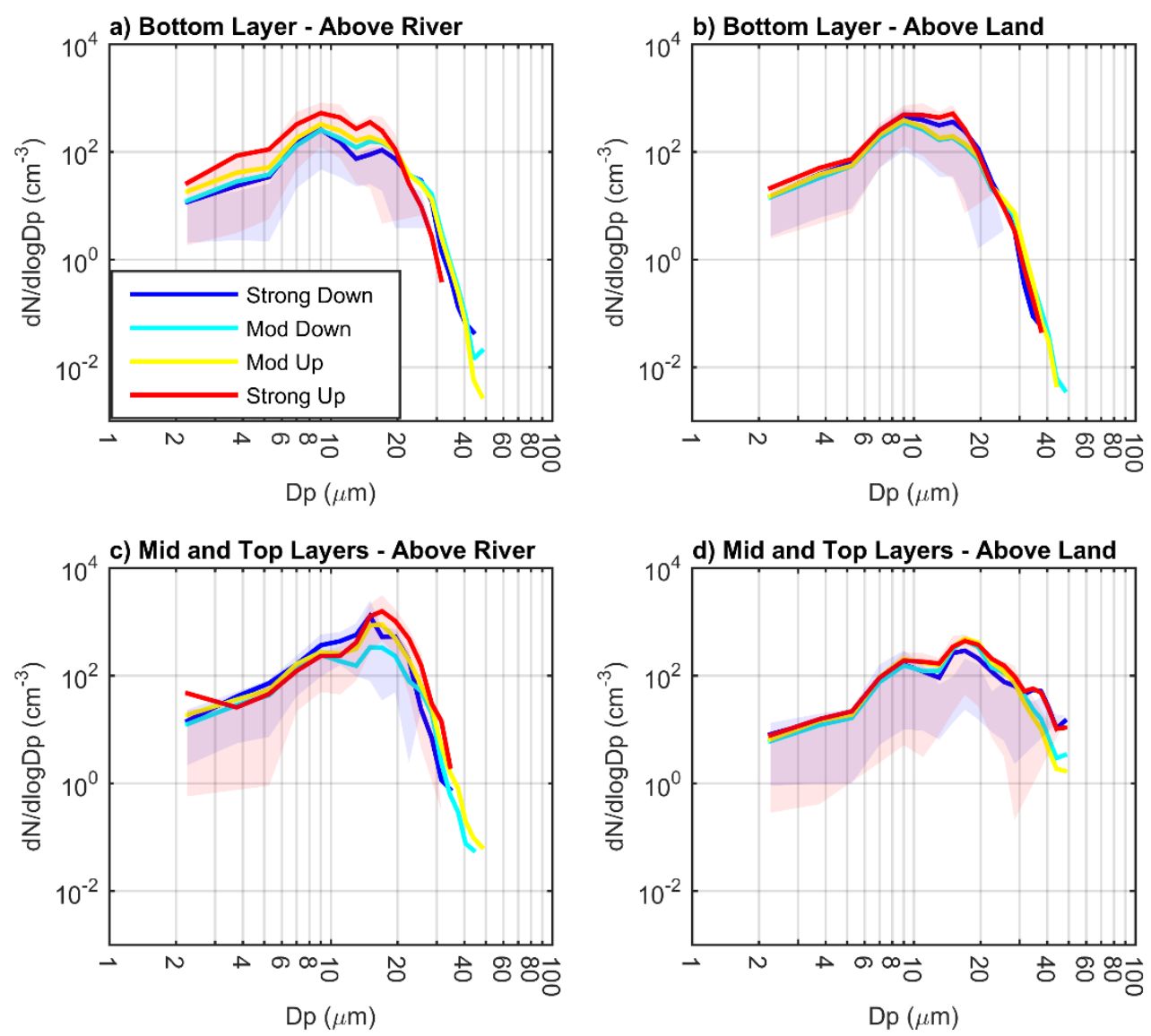

Figure S2: Averaged DSDs as function of altitude, presence of up/downdrafts and positioning relative to the rivers. The first row shows results for the bottom layer for DSDs (a) above rivers and (b) above land. The mid and top layers results are shown together in the second row for DSDs (c) above rivers and (d) above land. "Strong Down" means the presence of strong downdrafts, with velocities lower than $-2 \mathrm{~m} \mathrm{~s}^{-1}$. "Mod Down" is moderate downdrafts, with $-2 \mathrm{~m}$ $s^{-1}<w \leq 0$. "Mod Up" and "Strong Up" are the equivalents for updrafts. Their velocities ranges are, respectively, $0<w \leq 2 \mathrm{~m} \mathrm{~s}^{-1}$ and $w>2 \mathrm{~m} \mathrm{~s}^{-1}$. The shaded areas represent the dispersion between the $25 \%$ and $75 \%$ percentiles for the strong downdrafts (in blue) and updrafts (in red). 


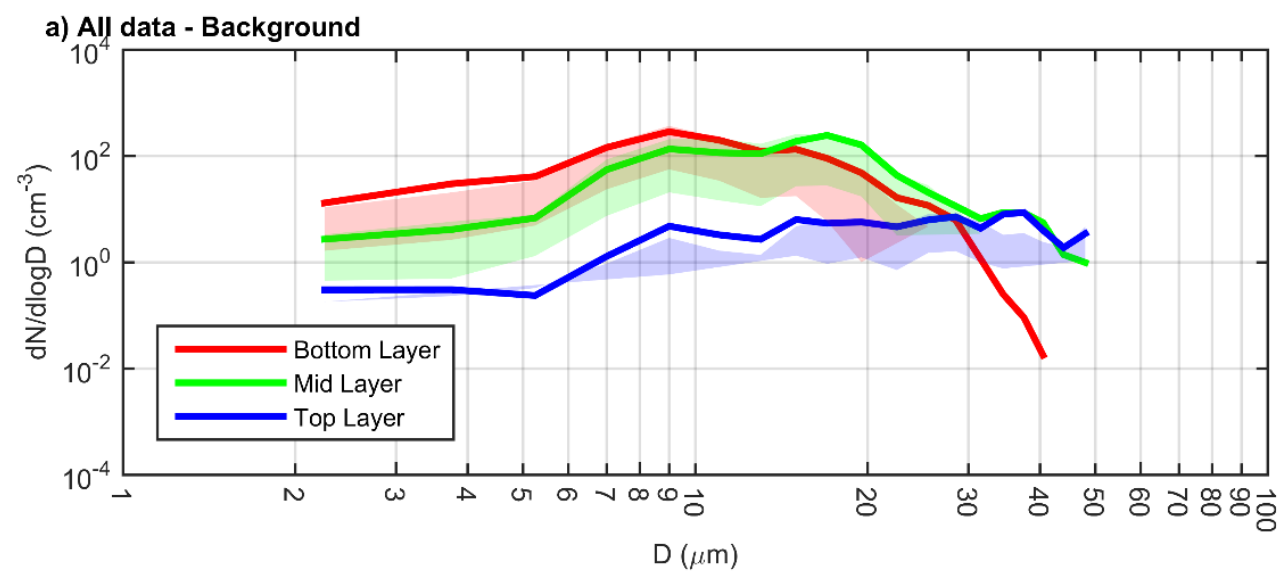

b) Above Land - Background
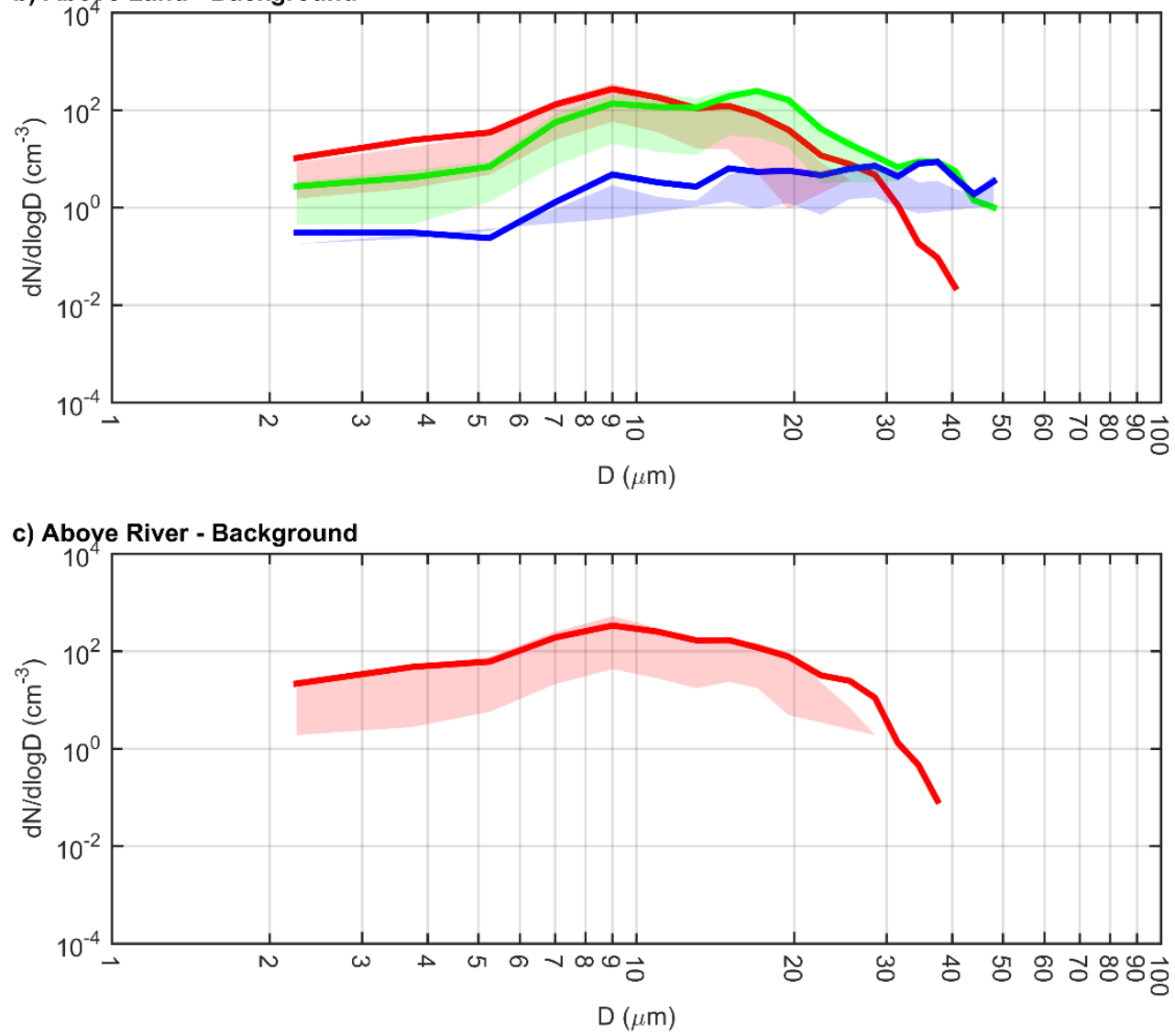

Figure S3: the same as Figure R.2, but only considering the points classified as background. 

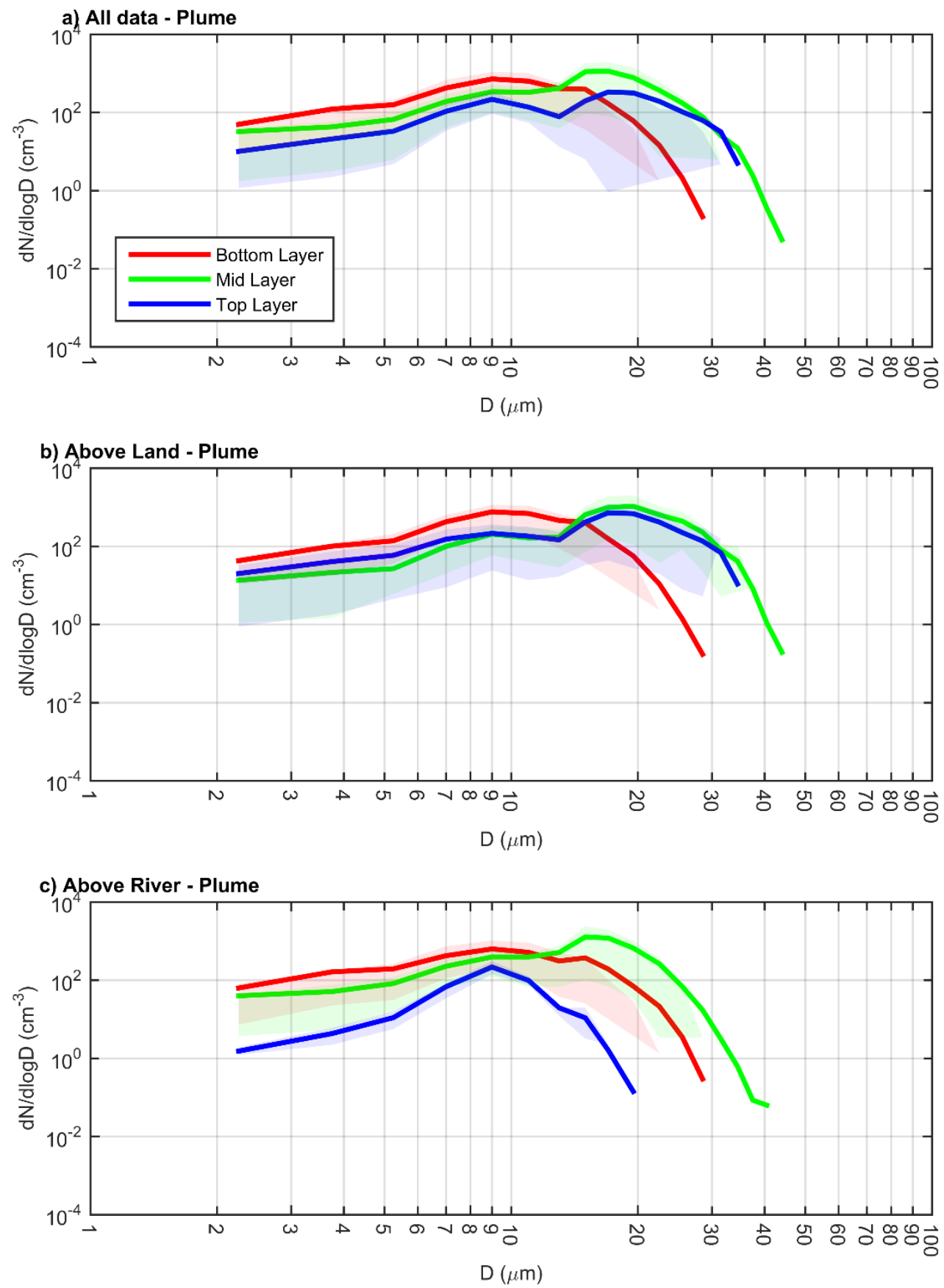

Figure S4: the same as Figure R.2, but only for the points classified as plume. 